\title{
Impact of sensor degradation on the MODIS NDVI time series
}

\author{
Dongdong Wang ${ }^{\mathrm{a}, *}$, Douglas Morton ${ }^{\mathrm{b}}$, Jeffrey Masek ${ }^{\mathrm{b}}$, Aisheng Wu ${ }^{\mathrm{c}}$, Jyoteshwar Nagol ${ }^{\mathrm{a}}$, \\ Xiaoxiong Xiong ${ }^{\mathrm{b}}$, Robert Levy ${ }^{\mathrm{c}}$, Eric Vermote ${ }^{\mathrm{a}}$, Robert Wolfe ${ }^{\mathrm{b}}$ \\ a Department of Geography, University of Maryland, College Park, MD 20742, USA \\ b NASA Goddard Space Flight Center, Greenbelt, MD 20771, USA \\ c Science Systems and Applications, Inc., 10210 Greenbelt Road, Lanham, MD 20706, USA
}

\section{A R T I C L E I N F O}

\section{Article history:}

Received 24 August 2011

Received in revised form 17 November 2011

Accepted 3 December 2011

Available online 14 January 2012

\section{Keywords:}

Sensor degradation

MODIS

NDVI

Time series

\begin{abstract}
A B S T R A C T
Time series of satellite data provide unparalleled information on the response of vegetation to climate variability. Detecting subtle changes in vegetation over time requires consistent satellite-based measurements. Here, the impact of sensor degradation on trend detection was evaluated using Collection 5 data from the Moderate Resolution Imaging Spectroradiometer (MODIS) sensors on the Terra and Aqua platforms. For Terra MODIS, the impact of blue band (Band 3, $470 \mathrm{~nm}$ ) degradation on simulated surface reflectance was most pronounced at near-nadir view angles, leading to a $0.001-0.004 \mathrm{yr}^{-1}$ decline in Normalized Difference Vegetation Index (NDVI) under a range of simulated aerosol conditions and surface types. Observed trends in MODIS NDVI over North America were consistent with simulated results, with nearly a threefold difference in negative NDVI trends derived from Terra (17.4\%) and Aqua (6.7\%) MODIS sensors during 2002-2010. Planned adjustments to Terra MODIS calibration for Collection 6 data reprocessing will largely eliminate this negative bias in detection of NDVI trends.
\end{abstract}

(c) 2011 Elsevier Inc. All rights reserved.

\section{Introduction}

Satellite data capture changes in the land surface, atmosphere, and ocean on diurnal to decadal time scales. Large and remote areas can be monitored using satellite data, and at nearly 40 years, the lengthening time series of satellite observations offer insight into climate impacts on human and natural systems. In particular, satellite-based studies of changes in vegetation phenology from seasonal, annual, and decadalscale temperature variability have received considerable attention in recent years (e.g., Goetz et al., 2005; Myneni et al., 1997; Wang et al., 2011). Detecting subtle changes in vegetation characteristics requires long time series of data from well-calibrated sensors (Slayback et al., 2003) and careful attention to uncertainties associated with atmospheric correction (Nagol et al., 2009) and sensor degradation.

Data from the Moderate Resolution Imaging Spectroradiometer (MODIS) sensors on board the NASA Terra (2000-present) and Aqua (2002-present) satellites provide a unique opportunity to assess the consistency of satellite-based measurements. Data products from both sensors are generated using consistent algorithms, and MODIS standard products support a range of science applications (e.g., Esaias et al., 1998; Justice et al., 2002; King et al., 2003). Recently, several studies have reported inconsistent results from the Terra and Aqua MODIS sensors, including estimates of ocean chlorophyll-a concentrations (Djavidnia

\footnotetext{
* Corresponding author at: Department of Geography, University of Maryland, 218 LeFrak Hall, College Park, MD 20742, USA. Tel.: + 1301405 4538; fax: + 13013149299. E-mail address: ddwang@umd.edu (D. Wang).
}

et al., 2010) and aerosols (Levy et al., 2010). Such discrepancies may impact the interpretation of time series or even the ability to detect temporal trends, especially for MODIS products that utilize data from both Terra and Aqua MODIS sensors.

Here, the impact of sensor degradation on trends in MODIS normalized difference vegetation index (NDVI) was analyzed over boreal forest and tundra cover types in North America, biomes previously identified as undergoing rapid climate-driven changes in productivity (de Jong et al., 2011; Pouliot et al., 2009). Degradation coefficients for each MODIS spectral band were calculated, and the time-varying trends in MODIS degradation were propagated through a simplified version of the MODIS atmospheric correction process. The simulated NDVI trends were then compared to observed trends in NDVI from the Terra and Aqua MODIS sensors over boreal North America. This study indicates that negative NDVI trends of up to $-0.004 \mathrm{yr}^{-1}$ can be attributed solely to degradation of the visible and near-infrared (NIR) bands aboard the Terra MODIS instrument. Therefore, careful consideration of sensor degradation may be warranted when interpreting decadal scale trends in land, ocean, and atmospheric constituents based on Collection 5 (C5) Terra MODIS data.

\section{Data and methods}

\subsection{MODIS top-of-atmosphere reflectance}

Sensor degradation is a common occurrence as satellite instruments age in the harsh space environment. In theory, sensor calibration using 
onboard apparatus can correct for sensor degradation, but in practice, the solar diffuser, stimulation lamps, and stability monitors needed for onboard calibration also change during mission life. A useful secondary source of information is to monitor reflectance trends with "pseudo-invariant" desert targets, which appear to be radiometrically and spectrally stable during the satellite era (Cosnefroy et al., 1996).

MODIS C5 top-of-atmosphere (TOA) reflectance data were collected over stable desert sites (Wu et al., 2008), endorsed by the Committee on Earth Observation Satellites (CEOS) (http://calval.cr.usgs.gov/sites catalog_map.php), to estimate degradation of the Terra (2000-2010) and Aqua (2002-2010) MODIS sensors over time. Level 1b TOA data for MODIS Bands 1 (red), 2 (NIR), and 3 (blue) were extracted from 16-day repeatable orbits over the site to maintain consistent sensor viewing angles. TOA reflectances were normalized using site-specific bi-directional reflectance function (BRDF) coefficients determined from the first three years of Terra and Aqua observations (Wu et al., 2008). The two sides (mirror sides 1 and 2) of MODIS scan lines had different performance and were treated separately. The BRDF normalized TOA data time series for each view angle (frame), spectral band, and mirror side were fitted using a second-order polynomial to estimate degradation for days since launch $(D S L)$ :

Degradation $=a_{0}+a_{1} \cdot D S L+a_{2} \cdot D S L^{2}$

where, $a_{0}, a_{1}$ and $a_{2}$ are regression coefficients. To estimate the impact of planned changes in sensor calibration for Collection 6 (C6) MODIS reprocessing (scheduled for late 2011), the C5 degradation coefficients were adjusted using the ratio of C5:C6 TOA reflectance for the Libya 4 site. Prototype C6 TOA data were generated over selected targets to evaluate the impact of calibration changes on MODIS data products. For the first time, C6 will incorporate calibration information from pseudo-invariant targets. A preview of the potential for $\mathrm{C} 6$ data to correct the bias in Terra MODIS products is provided here based on C6 calibration approach II, presented in May 2011 at MODIS Science Meeting (http://modis.gsfc.nasa.gov/sci_team/meetings/201105/). C6 data for the entire MODIS time series will not be available until at least 2012.
Therefore, the potential for continued degradation in C5 Terra data was also estimated by extending the fitted degradation curves to 2013.

\subsection{Simulation of atmospheric radiative transfer and atmospheric correction}

The time-dependent degradation coefficients for C5 Terra MODIS data were used to simulate the impact of sensor degradation on trends in NDVI over boreal North America during 2000-2010. The simulation included three major steps. First, 11-year time series of TOA reflectance were generated for forest and tundra cover types under a range of aerosol conditions, adjusting TOA values for sensor degradation over time. The proposed simulation approach was similar to the methods used to generate the MODIS surface reflectance product (MOD09, (Vermote et al., 2002; Vermote \& Kotchenova, 2008)), with several simplifying assumptions. The $6 \mathrm{~S}$ vector atmospheric radiative transfer model (Version 1.1, (Kotchenova et al., 2006)) was used. To improve computational efficiency, look-up tables (LUTs) of spherical albedo $(\rho)$, path reflectance $\left(r_{0}\right)$, and transmittance $(\gamma)$ were constructed. These LUTs were based on 15 aerosol optical depth (AOD) values (0.01-2.0), three aerosol models (continental, background desert, and biomass burning), and small angular intervals ( $5^{\circ}$ steps for solar and view zenith angles and $10^{\circ}$ steps for relative azimuth angle). The LUTs were used to relate TOA reflectance $(r)$ and surface reflectance $\left(r_{s}\right)$ (Liang, 2004):

$r=r_{0}+\frac{r_{s}}{1-r_{s} \rho} \gamma$

Mid-summer surface reflectance inputs $\left(r_{s}\right)$ for different cover types were derived from Aqua MODIS NDVI data (MYD13C2, (Huete et al., 2002)). NDVI values were binned in increments of 0.1 , and mean spectral reflectance values were estimated for each NDVI bin. Using Eq. (2), TOA reflectance $(r)$ for each NDVI bin was then estimated under different aerosol conditions using the LUTs described above. Finally, TOA reflectance values $(r)$ for each year were multiplied by the degradation coefficients estimated for C5 Terra MODIS data to simulate the TOA
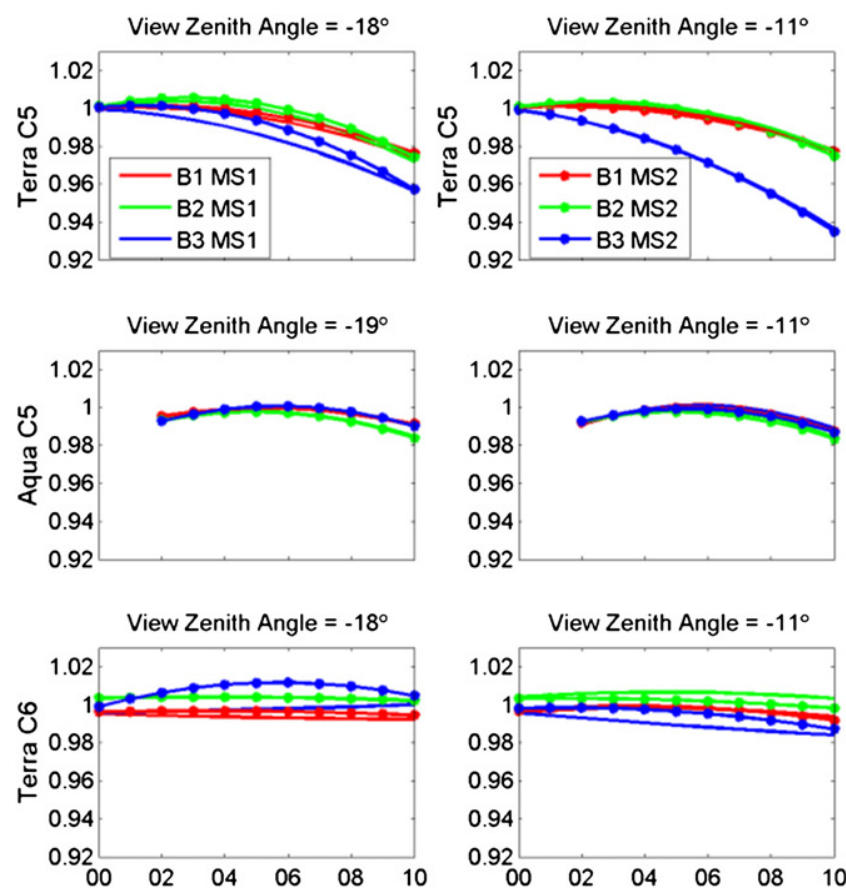
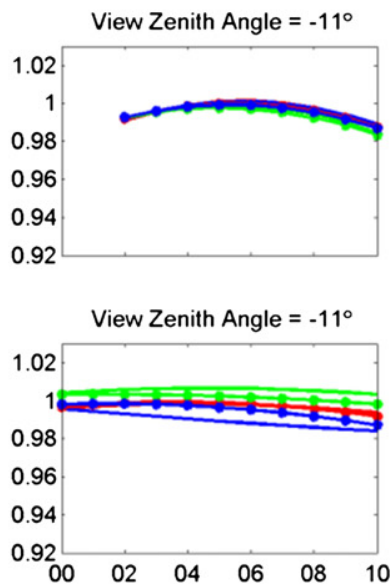
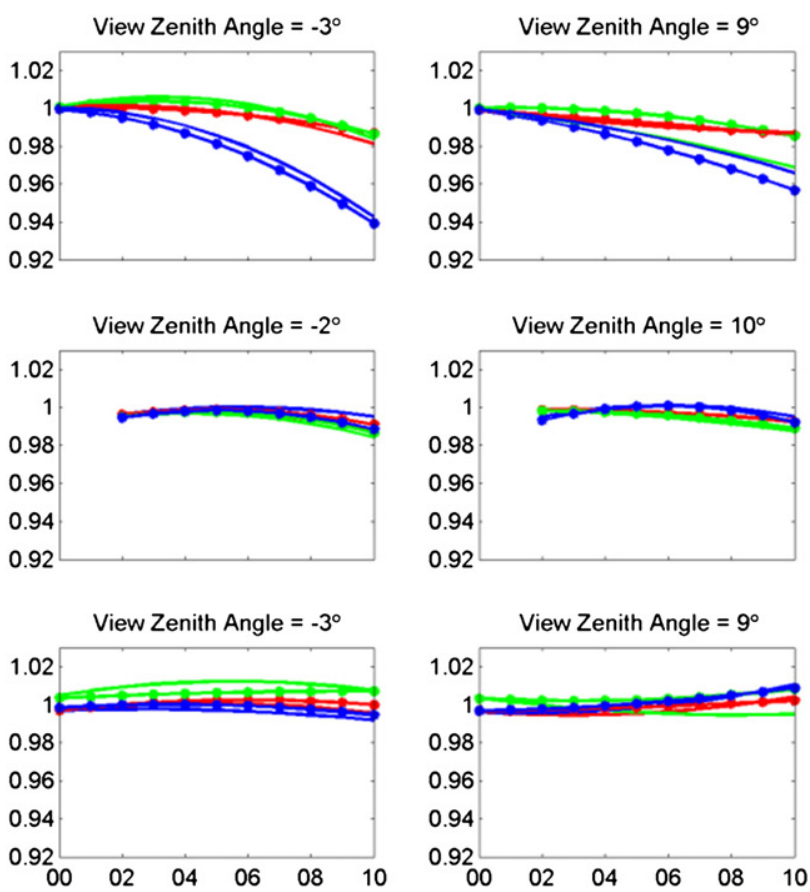

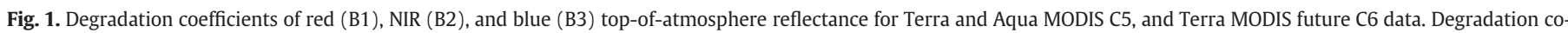
efficients were calculated separately for data from Mirror Side 1 (MS1) and Mirror Side 2 (MS2). Additional VZAs are shown in Fig. S1. 

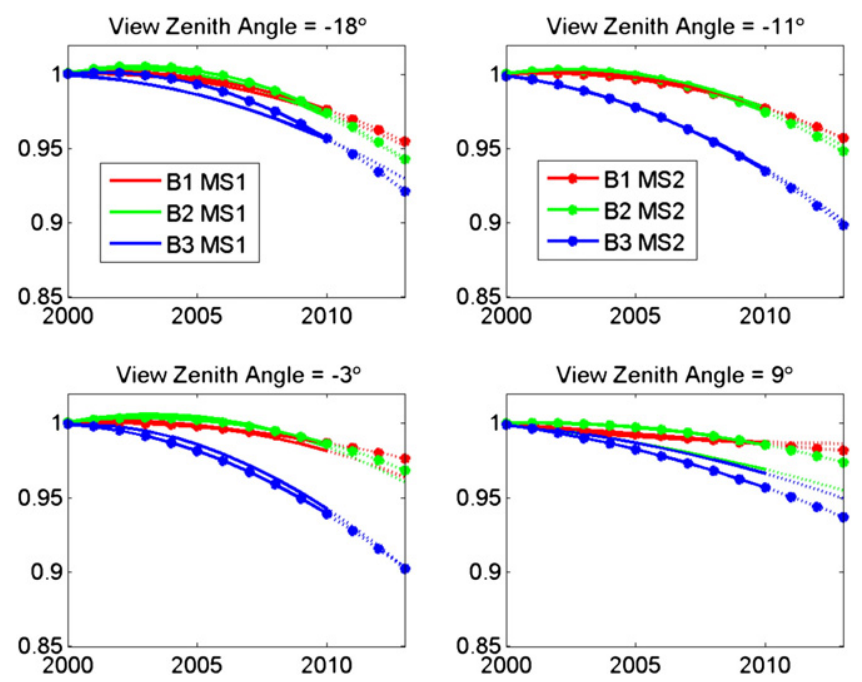

Fig. 2. Projected degradation of Terra MODIS C5 red (B1), near-infrared (B2), and blue (B3) top-of-atmosphere reflectance in years 2011-2013 (dashed lines) for four near-nadir VZAs.

reflectance $(\hat{r}$ ) observed by the sensor for each view zenith angle (VZA) and spectral band.

In the second step, simulated Terra MODIS surface reflectance values $\left(\hat{r}_{s}\right)$ were derived from the degraded TOA reflectance values $(\hat{r})$. A simplified Dense Dark Vegetation algorithm (Kaufman et al., 1997) was used to retrieve AOD. Two simplifications were made: 1) direct use of Band 3 surface reflectance, rather than estimating Band 3 reflectance using other MODIS bands (Kaufman et al., 1997), since C5 Terra MODIS degradation impacts were minimal for longer wavelengths, and 2) a single estimate of AOD at $550 \mathrm{~nm}$ from Band 3, thereby ignoring the spectrum dependence of AOD, because the aerosol model was known in the simulations. Given AOD, Eq. (2) can be solved to obtain surface reflectance $\left(\hat{r}_{s}\right)$ :

$\hat{r}_{s}=\frac{\hat{r}-r_{0}}{\gamma+\left(\hat{r}-r_{0}\right) \rho}$
Finally, time series of NDVI values were calculated using the estimated red and NIR surface reflectance values $\left(\hat{r}_{s}\right)$ (Huete et al., 2002) for each NDVI bin, year, and set of atmospheric conditions (AOD and aerosol model).

Two additional sets of simulations were developed to characterize the sensitivity of the results to specific input parameters for AOD and surface reflectance. In Scenario 1, the trend in the MODIS Terra AOD product (MOD08_D3) over land (Levy et al., 2010) was used instead of simulated AOD trends based on Band 3 degradation for the atmospheric correction procedure. This scenario tested the sensitivity of the results to estimates of blue band degradation, since the MODIS AOD product over land uses the blue reflectance in combination with other spectral information to estimate AOD (Remer et al., 2005). Scenario 2 examined the impact of sensor degradation in the red and NIR bands on simulated trends in NDVI. In this second scenario, the impact of blue band degradation was simulated while holding inputs for red and NIR reflectance constant. This scenario examined the degree to which degradation of the Terra MODIS Bands 1 and 2 partially compensates for Band 3 degradation over time.

\subsection{Monte Carlo simulation}

While the radiative transfer modeling estimated the effect of sensor degradation on individual NDVI time series, it did not address the issue of how such degradation might confound the extraction of vegetation trends from a large (e.g. continental) set of data. Of particular concern was estimating how the degradation-induced errors influence the results of detection of NDVI trends, given the stated uncertainty of the NDVI product. To explore this issue, a set of Monte Carlo simulations were used to examine the sensitivity of NDVI time series trend detection to artifacts from sensor degradation. Time series of C5 NDVI from peak growing season conditions in 2000-2010 were used as inputs to the Monte Carlo simulation. Each time series had an "actual" linear NDVI trend $\left(T_{0}\right)$ of varying magnitude $\left(-0.02 \mathrm{yr}^{-1}\right.$ to $\left.+0.02 \mathrm{yr}^{-1}\right)$, plus a linear degradation. Three degradation rates (no degradation and degradation of 0.001 and $0.003 \mathrm{NDVI} \mathrm{yr}^{-1}$ ) were used. Independent and identically distributed Gaussian errors were then added to the NDVI values. The standard deviation of the errors was set 0.015 , based on MODIS validation studies over AERONET sun photometer sites (http://modis-sr.ltdri.org/). The sensor degradation was then
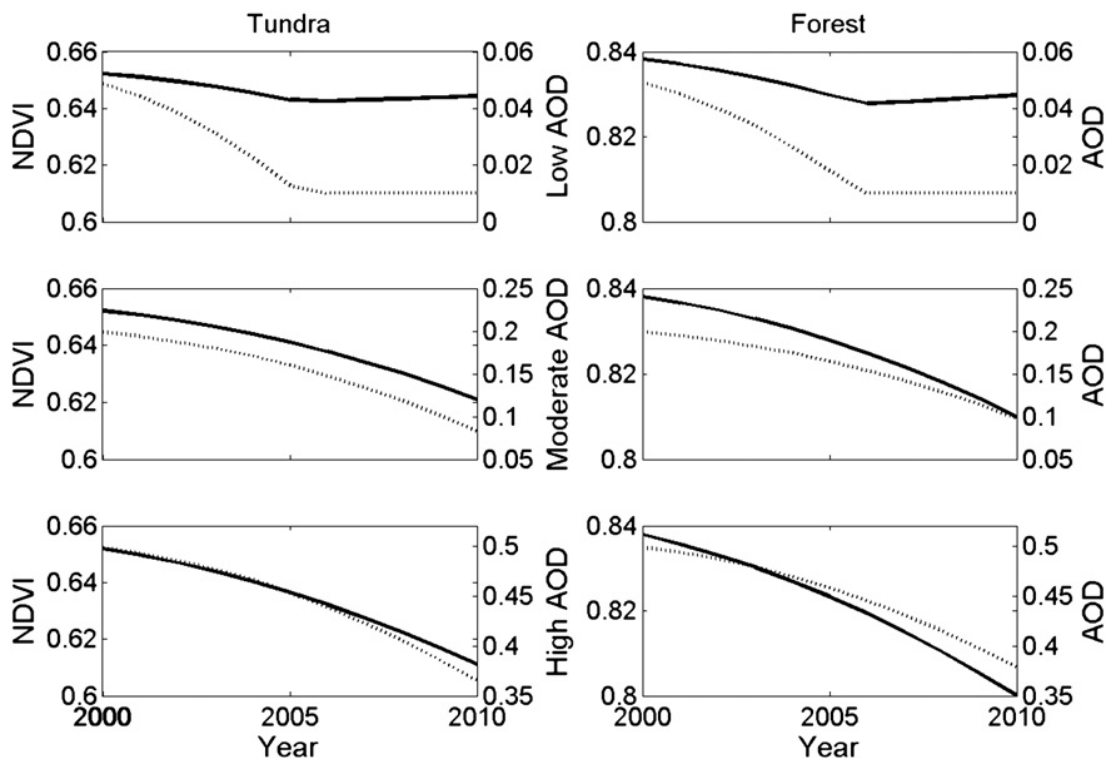

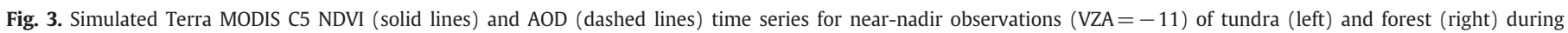
2000-2010 with low (0.05, top), moderate (0.2, middle), and high (0.5, bottom) AOD. Simulated NDVI and AOD time series for all VZAs are shown in Fig. S2 
Table 1

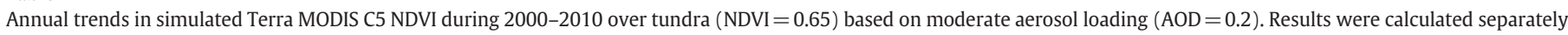

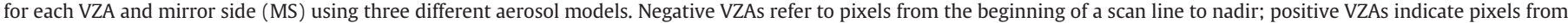
nadir to the end of a scan line. Stars "*" indicate no statistically significant trend. Values shown here are trends multiplied by $10^{3}$.

\begin{tabular}{|c|c|c|c|c|c|c|c|c|c|c|c|c|c|}
\hline \multicolumn{2}{|c|}{ View zenith angle } & \multirow{2}{*}{$\frac{-51}{*}$} & \multirow{2}{*}{$\frac{-42}{-0.8}$} & \multirow{2}{*}{$\frac{-32}{-0.8}$} & \multirow{2}{*}{$\frac{-28}{-1.2}$} & \multirow{2}{*}{$\frac{-18}{-2.3}$} & \multirow{2}{*}{$\frac{-11}{-3.1}$} & \multirow{2}{*}{$\frac{-3}{-2.7}$} & \multirow{2}{*}{$\frac{9}{-2.3}$} & \multirow{2}{*}{$\frac{17}{-1.1}$} & \multirow{2}{*}{$\frac{31}{-1.0}$} & \multirow{2}{*}{$\frac{43}{2.3}$} & \multirow{2}{*}{$\begin{array}{l}52 \\
3.4\end{array}$} \\
\hline MS1 & Continental & & & & & & & & & & & & \\
\hline & Desert & $*$ & -0.8 & -0.8 & -1.2 & -2.3 & -3.1 & -2.7 & -2.3 & -1.1 & -1.0 & 2.3 & 3.4 \\
\hline & Bio burning & $*$ & -0.6 & -0.7 & -1.0 & -1.9 & -2.8 & -2.4 & -2.1 & -0.9 & -0.8 & 2.2 & 3.2 \\
\hline \multirow[t]{3}{*}{ MS2 } & Continental & 0.3 & $*$ & -0.7 & -1.9 & -2.3 & -3.3 & -3.0 & -2.2 & -1.6 & -1.3 & 3.1 & 5.3 \\
\hline & Desert & 0.3 & $*$ & -0.7 & -1.8 & -2.3 & -3.3 & -3.1 & -2.2 & -1.6 & -1.3 & 3.1 & 5.3 \\
\hline & Bio burning & 0.3 & * & -0.5 & -1.6 & -2.0 & -2.9 & -2.7 & -1.9 & -1.4 & -1.1 & 2.8 & 4.8 \\
\hline
\end{tabular}

applied to generate the final NDVI time series. The time series were fit with a linear trend, using a $t$-test and $95 \%$ confidence interval to identify statistically significant linear trends.

Three variables (bias, ratio of false negatives, and ratio of false positives) were calculated for each set of Monte Carlo simulations. The bias in trend detection was estimated using the mean of all statistically significant trends, $\mu\left(T_{\text {Detected }}\right)$, and the actual trend, $T_{0}$ :

Bias $=\frac{\mu\left(T_{\text {Detected }}\right)-T_{0}}{T_{0}}$

The ratio of false negatives was estimated as the fraction of all time series $(N)$ in which detected trends did not have the correct positive or negative signs ( $n_{\text {incorrect }}$ ) or the trends did not pass the significance test $\left(n_{\text {no_sig }}\right)$ :

$F_{n}=\frac{n_{\text {incorrect }}+n_{\text {no_sig }}}{N}$

The ratio of false positives was estimated as the fraction of all statistically significant trends $\left(n_{\text {sig }}\right)$ in which statistically significant trends had the opposite signs $\left(n_{\text {incorrect }}\right)$ :

$F_{p}=\frac{n_{\text {incorrect }}}{n_{\text {sig }}}$

\subsection{MODIS NDVI trends for North America}

For comparison with the simulated impacts of sensor degradation described above, trends in C5 Terra and Aqua MODIS NDVI for boreal North America during 2002-2010 were mapped. High quality NDVI values from the C5 MODIS $500 \mathrm{~m}$ vegetation indices product (MOD13A1/MYD13A1, (Huete et al., 2002)) were analyzed. Data were selected for four 16-day composites during the growing season (starting on day of year 177, 193, 209, and 225 for Terra MODIS; day of year 185, 201, 217, and 233 for Aqua MODIS) to minimize impacts of vegetation phenology, and time series analyses were conducted separately for each compositing period. Only pixels with high quality NDVI observations in at least 6 out of the 9-year record were included in the analysis based on NDVI pixel reliability estimates. NDVI time series were fit with a linear trend, using a $t$-test and 95\% confidence interval to identify statistically significant linear trends. For pixels with significant NDVI trends in more than one compositing period, only pixels in which all significant trends had the same slope direction (positive or negative) were retained for the final map. A map of forest disturbances between 1990 and 2000 was used to exclude areas of fire damage or timber harvest predating the MODIS record (Masek et al., 2008), and likely disturbance areas during the MODIS era were excluded using a threshold of NDVI change between sequential observations $(>0.2)$.

\section{Results}

\subsection{Degradation of top-of-atmosphere reflectance}

Sensor degradation varied by spectral band, view angle, and mirror side (Fig. 1, S1). Overall, Aqua MODIS Bands $1-3$ showed $<2 \%$ change in TOA reflectance between 2002 and 2010, while Terra MODIS data exhibited substantial degradation, particularly at shorter wavelengths (Fig. 1, S1). Terra MODIS Band 3 had the most pronounced degradation, with a decrease of nearly $7 \%$ at near-nadir view angles over the past decade. By 2013, degradation of C5 Terra MODIS Band 3 may exceed $10 \%$ since launch (Fig. 2). Band 3 is not used directly for calculating NDVI; instead, degradation of Band 3 TOA reflectance over time will impact the calculation of surface reflectance in other spectral bands (Kotchenova et al., 2008; Vermote et al., 2002) and higher-level MODIS products, including NDVI. Planned calibration changes for C6 Terra MODIS data reprocessing will largely eliminate trends in TOA reflectance observed in the C5 time series (Fig. 1). Changes in TOA reflectance for prototype C6 Terra MODIS for $2000-2010$ were $<2 \%$ for most cases.

\subsection{Surface reflectance simulations}

Degradation of the Terra MODIS blue band resulted in decreasing NDVI trends (2000-2010) for simulated tundra and forest cover types under a range of aerosol conditions (Fig. 3). Changes in NDVI arose from the decreasing trend in retrieved AOD from degraded blue TOA reflectance. Three aerosol models were tested, yet the choice of aerosol model had little impact on retrieved AOD values in the simulations.

Table 2

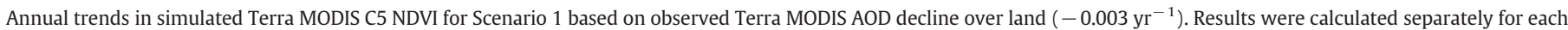

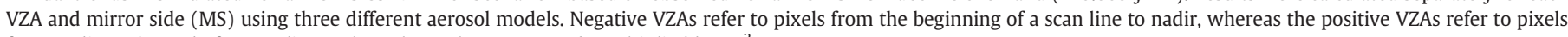
from nadir to the end of a scan line. Values shown here are trends multiplied by $10^{3}$.

\begin{tabular}{|c|c|c|c|c|c|c|c|c|c|c|c|c|c|}
\hline \multicolumn{2}{|c|}{ View zenith angle } & \multirow{2}{*}{$\frac{-51}{-1.2}$} & \multirow{2}{*}{$\frac{-42}{-1.0}$} & \multirow{2}{*}{$\frac{-32}{-0.8}$} & \multirow{2}{*}{$\frac{-28}{-0.8}$} & \multirow{2}{*}{$\frac{-18}{-0.5}$} & \multirow{2}{*}{$\frac{-11}{-0.5}$} & \multirow{2}{*}{$\frac{-3}{-0.5}$} & \multirow{2}{*}{$\frac{9}{-1.3}$} & \multirow{2}{*}{$\frac{17}{-0.4}$} & \multirow{2}{*}{$\frac{31}{-0.6}$} & \multirow{2}{*}{$\frac{43}{-0.3}$} & \multirow{2}{*}{$\frac{52}{-0.5}$} \\
\hline MS1 & Continental & & & & & & & & & & & & \\
\hline & Desert & -1.3 & -1.1 & -0.8 & -0.8 & -0.6 & -0.6 & -0.5 & -1.4 & -0.5 & -0.6 & -0.4 & -0.6 \\
\hline & Bio burning & -1.2 & -1.0 & -0.7 & -0.7 & -0.5 & -0.5 & -0.5 & -1.3 & -0.4 & -0.5 & -0.3 & -0.5 \\
\hline \multirow[t]{3}{*}{ MS2 } & Continental & -1.2 & -0.8 & -0.8 & -1.1 & -0.6 & -0.5 & -0.7 & -0.7 & -0.6 & -0.5 & -0.5 & -0.5 \\
\hline & Desert & -1.4 & -0.9 & -0.8 & -1.1 & -0.7 & -0.6 & -0.8 & -0.8 & -0.7 & -0.6 & -0.6 & -0.7 \\
\hline & Bio burning & -1.2 & -0.8 & -0.7 & -1.0 & -0.6 & -0.6 & -0.7 & -0.7 & -0.6 & -0.5 & -0.5 & -0.6 \\
\hline
\end{tabular}


Table 3

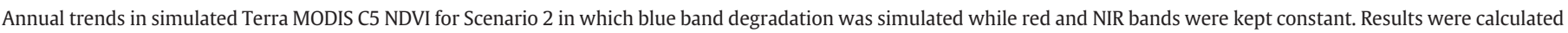

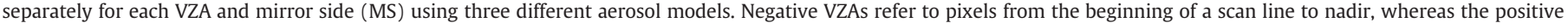
VZAs refer to pixels from nadir to the end of a scan line. Stars “*” indicate no statistically significant trend. Values shown here are trends multiplied by $10^{3}$.

\begin{tabular}{|c|c|c|c|c|c|c|c|c|c|c|c|c|c|}
\hline \multicolumn{2}{|c|}{ View zenith angle } & \multirow{2}{*}{$\frac{-51}{0.8}$} & \multirow{2}{*}{$\frac{-42}{-1.2}$} & \multirow{2}{*}{$\frac{-32}{-0.8}$} & \multirow{2}{*}{$\frac{-28}{-1.1}$} & \multirow{2}{*}{$\frac{-18}{-2.3}$} & \multirow{2}{*}{$\frac{-11}{-3.3}$} & \multirow{2}{*}{$\frac{-3}{-2.7}$} & \multirow{2}{*}{$\frac{9}{-2.3}$} & \multirow{2}{*}{$\frac{17}{-1.0}$} & \multirow{2}{*}{$\frac{31}{-1.5}$} & \multirow{2}{*}{$\frac{43}{1.9}$} & \multirow{2}{*}{$\frac{52}{*}$} \\
\hline MS1 & Continental & & & & & & & & & & & & \\
\hline & Desert & 0.8 & -1.2 & -0.8 & -1.1 & -2.3 & -3.3 & -2.7 & -2.4 & -1.0 & -1.5 & 1.9 & $*$ \\
\hline & Bio burning & 0.8 & -1.0 & -0.6 & -0.9 & -2.0 & -2.9 & -2.4 & -2.1 & -0.8 & -1.2 & 1.9 & $*$ \\
\hline \multirow[t]{3}{*}{ MS2 } & Continental & 0.2 & $*$ & $*$ & -1.8 & -2.2 & -3.4 & -3.1 & -2.3 & -1.6 & -1.9 & 2.5 & $*$ \\
\hline & Desert & 0.2 & $*$ & $*$ & -1.8 & -2.2 & -3.4 & -3.1 & -2.3 & -1.6 & -1.9 & 2.5 & $*$ \\
\hline & Bio burning & 0.3 & * & * & -1.5 & -1.9 & -3.0 & -2.7 & -2.0 & -1.4 & -1.6 & 2.3 & $*$ \\
\hline
\end{tabular}

For a moderate $(\mathrm{AOD}=0.2)$ and high $(\mathrm{AOD}=0.5)$ aerosol loading, retrieved AOD declined by approximately 0.1 between 2000 and 2010 . Under the low aerosol case, retrieved AOD reached the minimum simulation value $(0.01)$ as the blue reflectance decreased over time.

Negative trends in NDVI varied by VZA and aerosol loading (Table 1, S1). For moderate AOD, NDVI over forest and tundra declined by $0.003 \mathrm{yr}^{-1}$ at near-nadir VZA but $\leq 0.001 \mathrm{yr}^{-1}$ for $\mathrm{VZA} \geq 30^{\circ}$ from nadir. Simulations with high AOD had even stronger NDVI declines from sensor degradation (>0.004 $\mathrm{yr}^{-1}$, Table S1). In general, rates of declining NDVI were similar for tundra and forest types when comparing simulations with the same AOD and VZA (Fig. 3, S2). The impacts of sensor degradation on time-varying trends in NDVI were further elaborated in two additional experiments. In Scenario 1, which was based on trends in Terra AOD, declines in AOD $\left(0.003 \mathrm{yr}^{-1}\right)$ and NDVI $\left(0.001 \mathrm{yr}^{-1}\right)$ were approximately $1 / 3 \mathrm{rd}$ of the simulated declines based on degradation of Bands 1-3 (Table 2). In Scenario 2, excluding degradation of Terra MODIS red and NIR bands had little influence on the simulated NDVI decline at near-nadir VZAs (Table 3) since the degradation coefficients of red and NIR bands were similar (see Fig. 1).

Implementing calibration changes planned for C6 MODIS reprocessing largely eliminated trends in Terra MODIS C5 NDVI from sensor degradation over 2000-2010. For moderate AOD over tundra, a limited number of off-nadir view angles retained small positive NDVI trends $\left(0.001 \mathrm{yr}^{-1}\right)$ in simulations using C6 calibration information (Table 4).

\subsection{NDVI trend detection}

The systematic NDVI decrease from Terra MODIS sensor degradation could bias trend detection using C5 data. Based on the Monte Carlo simulations, the bias in trend detection could be $>500 \%$ when the actual NDVI change is small $\left(<0.002 \mathrm{yr}^{-1}\right)$ and the degradation rate is large $\left(0.003 \mathrm{yr}^{-1}\right)$. In this case, nearly all detected trends originated from sensor degradation rather than actual vegetation dynamics (Fig. 4). When degradation of NDVI was simulated at $0.003 \mathrm{yr}^{-1}$, almost half of simulated NDVI trends of $+0.006 \mathrm{yr}^{-1}$ could not be detected or were detected with the opposite sign. Even a degradation-based NDVI decline of $0.001 \mathrm{yr}^{-1}$ resulted in $>50 \%$ false negative detections of all NDVI trends between -0.002 and $+0.004 \mathrm{yr}^{-1}$. Overall, the Monte Carlo simulations demonstrate that the combined impact of sensor degradation and product uncertainties have a large impact on correct identification of trends in simulated C5 Terra MODIS NDVI.

\subsection{Terra and Aqua NDVI trends 2002-2010}

Both Terra and Aqua MODIS indicated regions with statistically significant negative (browning) and positive (greening) NDVI trends during 2002-2010 (Fig. 5). More than 95\% of trends detected using 2002-2010 C5 Terra and Aqua data for North America exceeded the estimated threshold for trend detection (0.004, Section 3.3). However, there was a threefold difference in the area of negative NDVI trends from Terra compared to Aqua, with large contiguous regions where Terra data indicated small negative NDVI trends. NDVI trends over boreal forest and tundra vegetation were small, with the mode of Aqua NDVI trend of +0.008 year $^{-1}$. Monte Carlo simulations (Section 3.2) suggest that these subtle changes fall within the range of time series trends that may be impacted by the combination of sensor degradation and product uncertainties. The combination of subtle changes in NDVI and comparable impacts from sensor degradation resulted in substantial differences in the spatial patterns of NDVI trends from Terra and Aqua. For pixels with statistically significant NDVI trends from both sensors, Terra NDVI trends were systematically smaller than Aqua NDVI trends during 2002-2010 (Fig. 6). The mean difference between Terra and Aqua NDVI trends was $-0.002 \mathrm{yr}^{-1}$ (Fig. 6). This value falls within the range of simulated declines in Terra MODIS NDVI from sensor degradation.

\section{Discussion and conclusions}

Degradation of the Terra MODIS blue band resulted in negative NDVI trends over tundra and boreal forest vegetation, with greater impacts at the near-nadir VZAs favored in the MODIS reflectance and NDVI products. Simulated impacts of sensor degradation were similar to observed trends in C5 Terra MODIS data for North America. Previous studies based on Advanced Very High Resolution Radiometer (AVHRR) and Landsat data have identified greening and browning trends of 0.005-0.01 NDVI yr ${ }^{-1}$ in the boreal and tundra regions of North America (de Jong et al., 2011; Pouliot et al., 2009). Monte Carlo simulations in this study suggest that up to half of all actual NDVI trends of this magnitude could be missed by Terra MODIS when both sensor degradation

Table 4

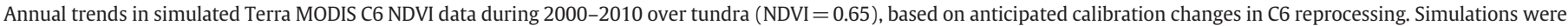

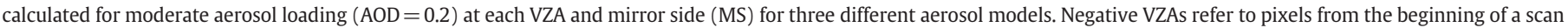

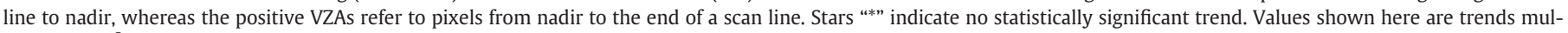
tiplied by $10^{3}$.

\begin{tabular}{|c|c|c|c|c|c|c|c|c|c|c|c|c|c|}
\hline \multicolumn{2}{|c|}{ View zenith angle } & \multirow{2}{*}{$\frac{-51}{*}$} & \multirow{2}{*}{$\frac{-42}{*}$} & \multirow{2}{*}{$\frac{-32}{1.3}$} & \multirow{2}{*}{$\frac{-28}{1.2}$} & \multirow{2}{*}{$\frac{-18}{*}$} & \multirow{2}{*}{$\frac{-11}{*}$} & \multirow{2}{*}{$\frac{-3}{*}$} & \multirow{2}{*}{$\frac{9}{*}$} & \multirow{2}{*}{$\begin{array}{l}17 \\
1.1\end{array}$} & \multirow{2}{*}{$\begin{array}{l}31 \\
*\end{array}$} & \multirow{2}{*}{$\begin{array}{l}43 \\
*\end{array}$} & \multirow{2}{*}{$\begin{array}{l}52 \\
*\end{array}$} \\
\hline MS1 & Continental & & & & & & & & & & & & \\
\hline & Desert & $*$ & $*$ & 1.3 & 1.2 & $*$ & $*$ & $*$ & $*$ & 1.1 & $*$ & $*$ & $*$ \\
\hline & Bio burning & $*$ & $*$ & 1.1 & 1.1 & $*$ & * & $*$ & * & 1.0 & * & $*$ & $*$ \\
\hline \multirow[t]{3}{*}{ MS2 } & Continental & $*$ & $*$ & 1.6 & $*$ & $*$ & $*$ & $*$ & $*$ & 1.0 & * & $*$ & $*$ \\
\hline & Desert & $*$ & $*$ & 1.6 & $*$ & $*$ & $*$ & * & $*$ & 1.0 & $*$ & $*$ & $*$ \\
\hline & Bio burning & $*$ & $*$ & 1.4 & $*$ & * & $*$ & * & $*$ & 0.8 & * & $*$ & $*$ \\
\hline
\end{tabular}



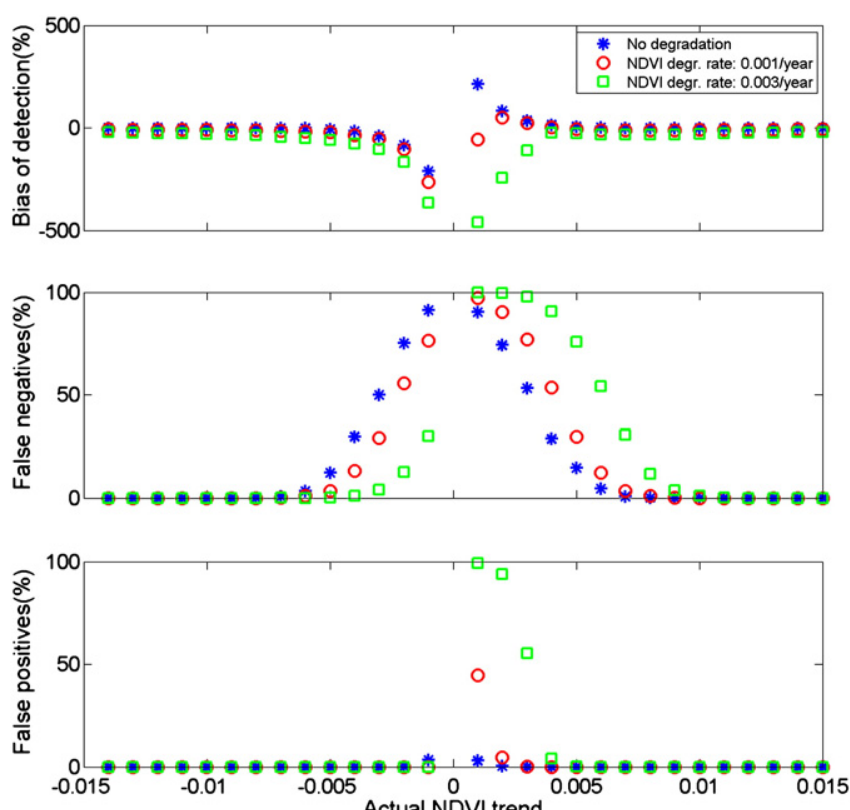

Fig. 4. Monte Carlo simulation results for the combined impacts of NDVI degradation and NDVI uncertainty (0.015) on trend detection. Detection bias (top), percentage of missing detections (middle), and percentage of false detections (bottom) were summarized for all statistically significant linear trends for different actual NDVI trend levels.

and product uncertainties are considered. Initial simulations using data processed with prototype C6 algorithms indicate no significant trends associated with sensor degradation for near-nadir VZAs. Thus, it is expected that C6 will largely remedy the issues described in this paper. Although MODIS data over the North American boreal forest and tundra were used in this study, the impacts of sensor degradation are not limited to this region because sensor degradation impacts all Terra/MODIS C5 TOA data and subsequent processing for land and atmosphere products. In addition, degradation of Terra MODIS C5 data impacts ongoing efforts to inter-calibrate data from current and previous generations of Earth observing satellites to generate long time series of NDVI (e.g., Fensholt \& Sandholt, 2005; van Leeuwen et al., 2006). Based on temporal trends in C5 Terra MODIS data identified in this study, we recommend that users rely on Aqua MODIS data for time series analysis of vegetation changes and inter-calibration of MODIS, AVHRR, and the next generation of polar orbiting satellites (e.g., the NPOESS Preparatory Project-NPP) until C6 data are available for the Terra MODIS time series.
Studies of subtle trends in vegetation cover may be particularly sensitive to artifacts from Terra MODIS sensor degradation. Many land products select near-nadir observations where sensor degradation was most pronounced, and the small negative bias in Terra MODIS NDVI from sensor degradation may be more easily confused with real browning trends over vegetation than cloud contamination or other sensor artifacts. Given the non-linear declines in Band 3 TOA reflectance, studies that compare annual or seasonal anomalies in C5 Terra MODIS NDVI may also amplify artifacts from sensor degradation. Many other applications will be less sensitive to artifacts from sensor degradation, such as studies that use longer wavelengths or applications based on large and persistent changes in surface reflectance associated with land cover change.

Terra MODIS Band 3 degradation may also account for observed discrepancies in AOD from Terra and Aqua MODIS sensors. Levy et al. (2010) noted that Terra's AOD record showed a negative trend compared to ground-based AERONET sunphotometers while comparisons between AERONET and Aqua AOD showed no trend. Over land, MODIS aerosol retrieval is based on three bands, including Band 3 (Remer et al., 2005). Sensitivity tests suggest that $\geq 3 \%$ degradation of Band 3 is sufficient to explain the trend in Terra MODIS versus AERONET comparison. As with studies of vegetation, C5 Aqua MODIS data should be used for studies of inter-annual variability in aerosols until Band 3 degradation can be addressed in $\mathrm{C} 6$ reprocessing.

Sensor calibration is critical for time series analyses. Long time series desired by the science community necessitate consistent calibration throughout the entire mission lifetime. In the case of MODIS, calibration efforts now utilize onboard equipment, monthly lunar observations, and pseudo-invariant ground targets to determine timedependent and wavelength-dependent changes in the reflective solar bands. Instrument characteristics and on-orbit malfunctions also complicate sensor calibration. The observed degradation on Terra MODIS is thought to be associated with on-orbit changes in the bi-directional reflectance characteristics of the solar diffuser from those obtained in pre-launch tests, which is used along with measurements by the solar diffuser stability monitor to derive onorbit degradation rates. Following an anomaly with the Terra MODIS solar diffuser in 2003, the solar diffuser door was fixed in the "open" position to keep the instrument screen permanently in place (Xiong \& Barnes, 2006). Since that change, the rate of Terra MODIS degradation has increased. These issues highlight the importance of having multiple lines of evidence for assessing sensor calibration, including the use of both on-board mechanisms and invariant ground targets.

Terra MODIS C5 data remain an important source of information for a range of science applications. However, time series analysis of

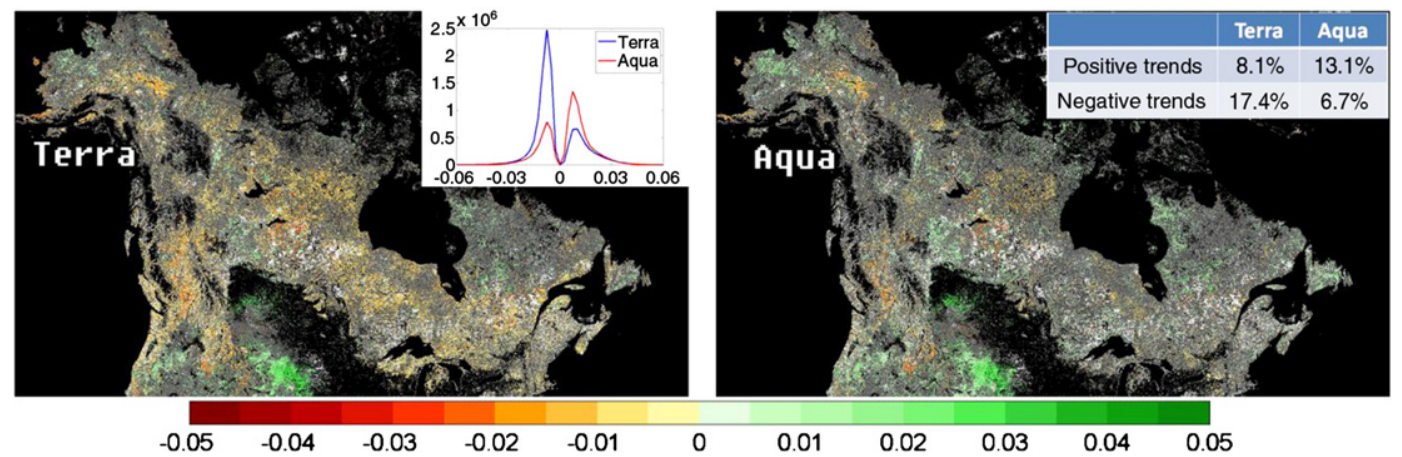

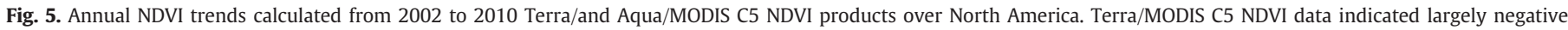

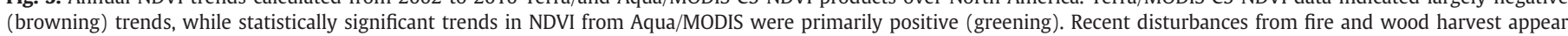
white, while water, cropland, and barren land cover types appear black. Inset panels summarize statistically significant NDVI trends over land from each dataset. 


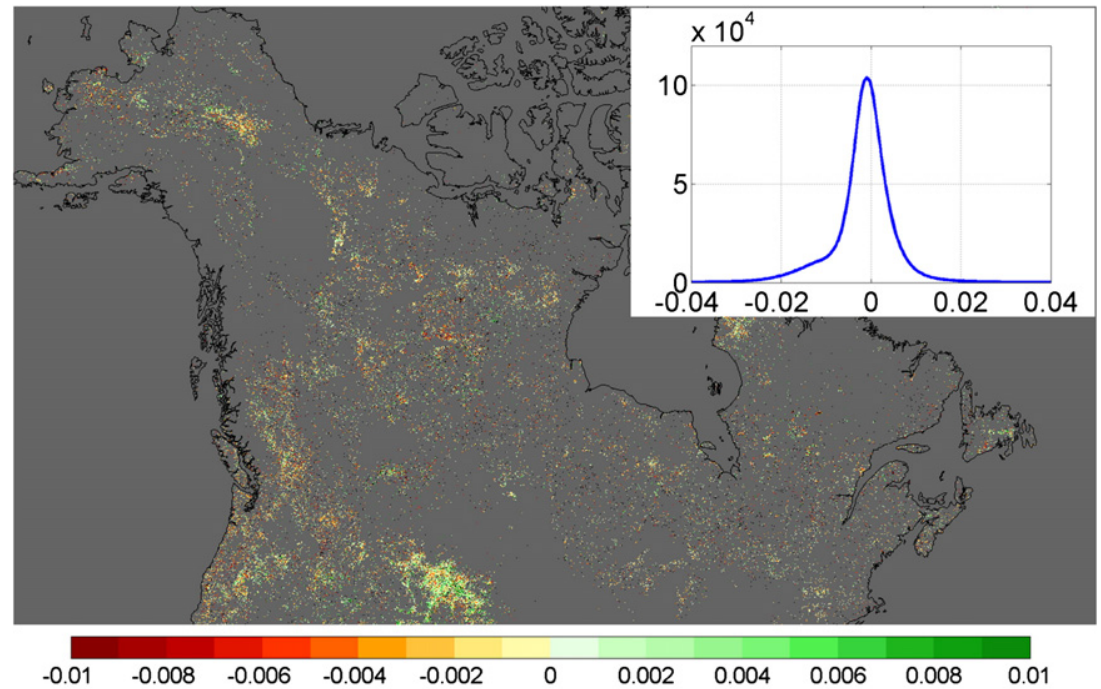

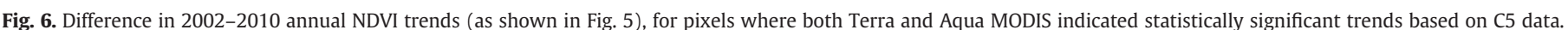

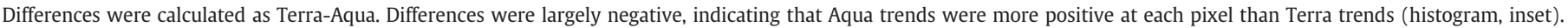
Overall, pixels detected as significant trends in both datasets represented $34.3 \%$ of trend pixels detected by Terra and $44.0 \%$ of pixels detected by Aqua.

vegetation or aerosol properties based directly or indirectly on C5 Terra MODIS Band 3 data may be sensitive to impacts of sensor degradation. Errors from sensor degradation remain within the uncertainties of the retrieval algorithm and instrument characteristics (Vermote \& Kotchenova, 2008). However, even small trends in sensor performance may influence time series analysis. C6 data reprocessing will likely alleviate the problems identified in this study, yet MODIS data users should consider the potential for sensor degradation to impact their analysis, given that the aging MODIS sensors will remain vulnerable to similar problems in the future.

\section{Appendix A. Supplementary data}

Supplementary data to this article can be found online at doi:10. 1016/j.rse.2011.12.001.

\section{References}

Cosnefroy, H. N., Leroy, M., \& Briottet, X. (1996). Selection and characterization of Saharan and Arabian desert sites for the calibration of optical satellite sensors. Remote Sensing of Environment, 58, 101-114.

de Jong, R., de Bruin, S., de Wit, A., Schaepman, M. E., \& Dent, D. L. (2011). Analysis of monotonic greening and browning trends from global NDVI time-series. Remote Sensing of Environment, 115, 692-702.

Djavidnia, S., Melin, F., \& Hoepffner, N. (2010). Comparison of global ocean colour data records. Ocean Science, 6, 61-76.

Esaias, W. E., Abbott, M. R., Barton, I., Brown, O. B., Campbell, J. W., Carder, K. L., et al (1998). An overview of MODIS capabilities for ocean science observations. IEEE Transactions on Geoscience and Remote Sensing, 36, 1250-1265.

Fensholt, R., \& Sandholt, I. (2005). Evaluation of MODIS and NOAA AVHRR vegetation indices with in situ measurements in a semi-arid environment. International Journal of Remote Sensing, 26, 2561-2594.

Goetz, S. J., Bunn, A. G., Fiske, G. J., \& Houghton, R. A. (2005). Satellite-observed photosynthetic trends across boreal North America associated with climate and fire disturbance. Proceedings of the National Academy of Sciences of the United States of America, 102, 13521-13525.

Huete, A., Didan, K., Miura, T., Rodriguez, E. P., Gao, X., \& Ferreira, L. G. (2002). Overview of the radiometric and biophysical performance of the MODIS vegetation indices. Remote Sensing of Environment, 83, 195-213.

Justice, C. O., Townshend, J. R. G., Vermote, E. F., Masuoka, E., Wolfe, R. E., Saleous, N., et al. (2002). An overview of MODIS Land data processing and product status. Remote Sensing of Environment, 83, 3-15.

Kaufman, Y. J., Tanre, D., Remer, L. A. Vermote, E. F., Chu, A. \& Holben, B. N. (1997). Operational remote sensing of tropospheric aerosol over land from EOS moderate resolution imaging spectroradiometer. Journal of Geophysical Research-Atmospheres, 102, 17051-17067.
King, M. D., Menzel, W. P., Kaufman, Y. J., Tanre, D., Gao, B. C., Platnick, S., et al. (2003). Cloud and aerosol properties, precipitable water, and profiles of temperature and water vapor from MODIS. IEEE Transactions on Geoscience and Remote Sensing, 41, 442-458.

Kotchenova, S. Y., Vermote, E. F., Levy, R., \& Lyapustin, A. (2008). Radiative transfer codes for atmospheric correction and aerosol retrieval: intercomparison study. Applied Optics, 47, 2215-2226.

Kotchenova, S. Y., Vermote, E. F., Matarrese, R., \& Klemm, F. J. (2006). Validation of a vector version of the $6 \mathrm{~S}$ radiative transfer code for atmospheric correction of satellite data. Part I: Path radiance. Applied Optics, 45, 6762-6774.

Levy, R. C. Remer, L. A, Kleidman, R. G, Mattoo, S, Ichoku, C., Kahn, R, et al. (2010). Global evaluation of the Collection 5 MODIS dark-target aerosol products over land. Atmospheric Chemistry and Physics, 10, 10399-10420.

Liang, S. L. (2004). Quantitative remote sensing of land surfaces. Hoboken, New Jersey: John Wiley \& Sons, Inc.

Masek, J. G., Huang, C. Q., Wolfe, R., Cohen, W., Hall, F., Kutler, J., et al. (2008). North American forest disturbance mapped from a decadal Landsat record. Remote Sensing of Environment, 112, 2914-2926.

Myneni, R. B., Keeling, C. D., Tucker, C. J., Asrar, G., \& Nemani, R. R. (1997). Increased plant growth in the northern high latitudes from 1981 to 1991. Nature, 386, 698-702.

Nagol, J. R., Vermote, E. F., \& Prince, S. D. (2009). Effects of atmospheric variation on AVHRR NDVI data. Remote Sensing of Environment, 113, 392-397.

Pouliot, D., Latifovic, R., \& Olthof, I. (2009). Trends in vegetation NDVI from $1 \mathrm{~km}$ AVHRR data over Canada for the period 1985-2006. International Journal of Remote Sensing, 30, 149-168.

Remer, L. A., Kaufman, Y. J., Tanre, D., Mattoo, S., Chu, D. A., Martins, J. V., et al. (2005). The MODIS aerosol algorithm, products, and validation. Journal of the Atmospheric Sciences, 62, 947-973.

Slayback, D. A., Pinzon, J. E., Los, S. O., \& Tucker, C. J. (2003). Northern hemisphere photosynthetic trends 1982-99. Global Change Biology, 9, 1-15.

van Leeuwen, W. J. D., Orr, B. J., Marsh, S. E., \& Herrmann, S. M. (2006). Multi-sensor NDVI data continuity: Uncertainties and implications for vegetation monitoring applications. Remote Sensing of Environment, 100, 67-81.

Vermote, E. F., El Saleous, N. Z., \& Justice, C. O. (2002). Atmospheric correction of MODIS data in the visible to middle infrared: First results. Remote Sensing of Environment, 83, 97-111.

Vermote, E. F., \& Kotchenova, S. (2008). Atmospheric correction for the monitoring of land surfaces. Journal of Geophysical Research-Atmospheres, 113.

Wang, X. H., Piao, S. L., Ciais, P., Li, J. S., Friedlingstein, P., Koven, C., et al. (2011). Spring temperature change and its implication in the change of vegetation growth in North America from 1982 to 2006. Proceedings of the National Academy of Sciences of the United States of America, 108, 1240-1245.

Wu, A., Angal, A., Xiong. X., \& Cao, C. (2008). Monitoring MODIS calibration stability of visible and near-IR bands from observed top-of-atmosphere BRDF-normalized reflectances over Libyan Desert and Antarctic surfaces. Proceedings of SPIE, 7081, 708113.

Xiong, X. X., \& Barnes, W. (2006). An overview of MODIS radiometric calibration and characterization. Advances in Atmospheric Sciences, 23, 69-79. 